\title{
Process identification of soil erosion in steep mountain regions
}

\author{
N. Konz ${ }^{1,2}$, D. Baenninger ${ }^{1}$, M. Konz ${ }^{3}$, M. Nearing ${ }^{4}$, and C. Alewell ${ }^{1}$ \\ ${ }^{1}$ Institute of Environmental Geosciences, University of Basel, Bernoullistr. 30, 4056 Basel, Switzerland \\ ${ }^{2}$ Agroscope Reckenholz-Tänikon Research Station ART, Reckenholzstr. 191, 8046 Zürich, Switzerland \\ ${ }^{3}$ ETH Zurich, Institute of Environmental Engineering, Hydrology and Water Resources Management Wolfgang-Pauli-Str. 15, \\ 8093 Zurich, Switzerland \\ ${ }^{4}$ United States Department of Agriculture, Agriculture Research Service (USDA-ARS), National Soil Erosion Research \\ Laboratory, West Lafayette, IN, USA
}

Received: 25 September 2008 - Published in Hydrol. Earth Syst. Sci. Discuss.: 9 March 2009

Revised: 2 July 2009 - Accepted: 25 March 2010 - Published: 15 April 2010

\begin{abstract}
Mountainous soil erosion processes were investigated in the Urseren Valley (Central Switzerland) by means of measurements and simulations. The quantification of soil erosion was performed on hill slope scale $(2.20 \mathrm{~m})$ for three different land use types: hayfields, pastures with dwarf shrubs and pastures without dwarf shrubs with three replicates each. Erosion rates during growing season were measured with sediment traps between June 2006 and November 2007. Long-term soil erosion rates were estimated based on Cs- 137 redistribution. In addition, soil moisture and surface flow were recorded during the growing season in the field and compared to model output. We chose the WEPP model (Water Erosion Prediction Project) to simulate soil erosion during the growing season. Model parameters were determined in the field (slope, plant species, fractional vegetation cover, initial saturation level), by laboratory analyses (grain size, organic matter) and by literature study. The WEPP model simulates sheet erosion processes (interrill and splash erosion processes, please note that no rill erosion occurs at our sites). Model output resulted in considerable smaller values than the measured erosion rates with sediment traps for the same period. We attribute the differences to observed random gravity driven erosion of soil conglomerates. The Cs-137 measurements deliver substantially higher mean annual erosion rates, which are most likely connected to snow cover related processes such as snow gliding and avalanche activities.
\end{abstract}

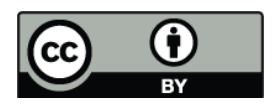

Correspondence to: N. Konz (n.konz@gmx.ch)

\section{Introduction}

Soil erosion is a major environmental problem in many parts of the world (Nearing et al., 2004). The dominant processes in agricultural lowlands such as splash, rill and interrill erosion are well investigated in numerous studies over the last decades (e.g. Govers et al., 1999; Hessel et al., 2003; Walling and $\mathrm{He}, 1999)$. However, less attention has been paid to erosion processes in mountainous systems, where the extreme climate and steep slope angles trigger soil erosion processes. Gravity forcing is a crucial process in these environments in combination with animal activity during the growing season. Rill erosion processes are not observed in unploughed mountainous environments. In the following the term sheet erosion summarizes erosion through unconcentrated flow (often referred to as interrill erosion) and splash erosion processes. In addition, snow cover related mechanical friction and/or abrasion processes will occur during winter time and may also have a significant influence on erosion rates in mountainous environments. Water induced soil erosion in mountainous regions is greatly influenced by land use and management as well as by climate, extreme topography and soil erodibility (Alewell et al., 2008; Simonato et al., 2002). Following the above discussion, the term soil erosion is not referring to landslides or rapid mass movements in shallow soils in this study.

Since snow dynamics make it difficult to measure soil erosion in mountainous regions throughout the year, most of the erosion measurements have been conducted during the growing season without the influence of snow (Descroix and Mathys, 2003; Felix and Johannes, 1995; Isselin-Nondedeu and Bedecarrats, 2007). Erosion rates in alpine grasslands measured by Felix and Johannes (1995) were between 0.1

Published by Copernicus Publications on behalf of the European Geosciences Union. 


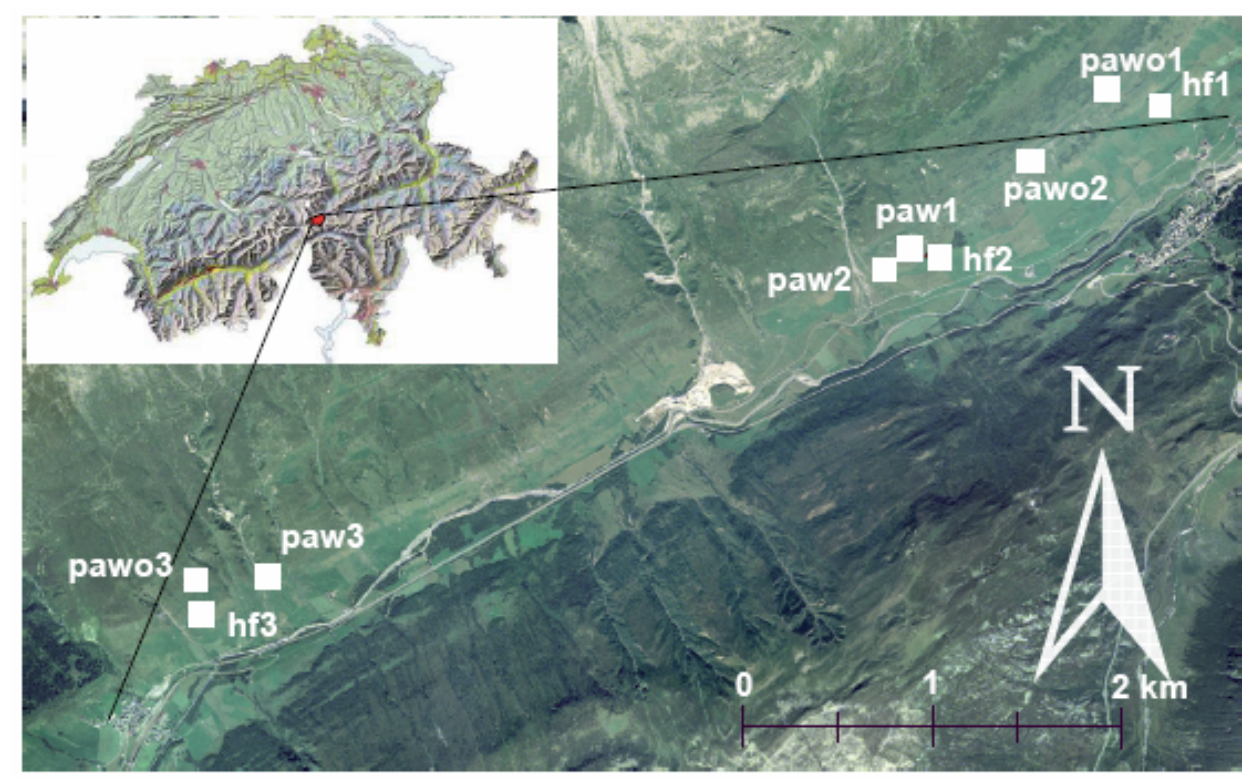

Fig. 1. The Urseren Valley in Central Switzerland and location of the investigation sites with three land use types: hayfield (hf), pasture without dwarf shrubs (pawo) and pasture with dwarf shrubs (paw). The meteorological station is on the valley bottom at an elevation of about $1400 \mathrm{~m}$ a.s.l., $1 \mathrm{~km}$ north-east of measurement station hf 1 .

and $10 \mathrm{~kg} \mathrm{ha}^{-1}$ for the growing season. Isselin- Nondedeu and Bedecarrats (2007) measured the influence of several plants on soil erosion. They found considerable difference with Festuca Alpina having the highest amount of sediment deposition.

Climate change has an effect on the increase of thawing days in mountainous regions (Appenzeller et al., 2008). Snowmelt is reported to occur earlier in spring due to rising temperatures (Laternser and Schneebeli, 2003). This indicates a higher amount of precipitation in the form of rain compared to snow. Surface runoff in winter and spring is predicted to be higher with potentially increasing soil erosion during times of sparse or no vegetation cover (Fuhrer et al., 2006). A better understanding of mountainous erosion processes is therefore a prerequisite for all types of land use and climate change assessment studies and the development of mitigation concepts.

This study aims at determining the dominant erosion processes in mountainous environments. The assessment is based on a combined observation and modeling approach. We used the Water Erosion Prediction Project Model (WEPP) because it is a well established tool to simulate water erosion and sediment yield. WEPP has been applied in various geographic locations across the United States (e.g. Huang et al., 1996; Laflen et al., 2004; Savabi et al., 1993), in Australia (Yu and Rosewell, 2001) and in Europe (Brazier et al., 2000; Gronsten and Lundekvam, 2006; Pieri et al., 2007; Raclot and Albergel, 2006). The application of WEPP in steep mountainous environments has been tested once in the Italian Alps by Simonato et al. (2002). The authors suc- cessfully reproduced measured erosion rates. Measurements of erosion rates were done with sediment traps during the growing season and mean annual erosion was measured by means of Cs-137 activity over the last 22 years to obtain additional information of erosion processes for mountainous regions. Our hypothesis was that the differences between the model results and the measurements can be attributed to processes specific for mountainous regions that are less relevant in low lands and thus not covered by the model.

\section{Materials and methods}

\subsection{Investigation area}

The study area is located in Central Switzerland (Canton Uri) in the Urseren Valley (Fig. 1). The sub-catchment of the Furka Reuss has an area of about $30 \mathrm{~km}^{2}$. The elevation of the WE oriented mountain valley ranges from about $1400 \mathrm{~m}$ a.s.l. to about $2500 \mathrm{~m}$ a.s.l. Measured mean annual rainfall from 1986 to 2008 is $1516 \mathrm{~mm}$, and mean air temperature at the weather station $\left(1400 \mathrm{~m}\right.$ a.s.l.) is $3.1^{\circ} \mathrm{C}$ (MeteoSwiss, 2007). The valley is snow-covered from about November to April with the maximum snow height occurring usually in March. The mean annual snowfall from 1986 to 2008 is $448 \mathrm{~mm}$ water equivalent. Discharge is usually dominated by snowmelt from May to June. Important contributions to the flow regime are early autumn floods.

The dominant land use types in the valley are hayfield with hay harvesting near the valley bottom, and pasture further upslope. Siliceous material is dominant, forming cambic 
podzols (anthric) IUSS Working Group (2006). Vegetation shows strong anthropogenic influences due to centuries of pasturing (Kaegi, 1973). The characteristic of these soils is a migration (M-horizon) horizon within the upper about $100 \mathrm{~cm}$ that is caused by sedimentation in the past. The thickness of the M-horizon is between 5 and $45 \mathrm{~cm}$.

\subsection{Experimental plots}

The experimental plots $\left(\sim 40 \mathrm{~m}^{2}\right)$ are situated at the southfacing slope at an altitude of 1550 to $1800 \mathrm{~m}$ a.s.l. (Fig. 1). Three different land use types with three replicates each were investigated. The land use types are hayfield (hf1, hf2, hf3), pasture with dwarf shrubs (paw1, paw2, paw3) and pasture without dwarf shrubs (pawo1, pawo2, pawo3). The slopes of all plots were in the range of $35^{\circ}$ to $39^{\circ}$. Soil textures of all 9 plots are listed in Table 1. The hayfield vegetation is dominated by Trifolium pratense ssp. Partense, Festuca sp., Thymus serpyllum and Agrostis capillaries. Pasture with dwarf shrubs are dominated by Calluna vullgaris, Vaccinium myrtillus, Festuca violacea, Agrostis capillaries and Thymus serpyllum. Dominant plant species on pastures without dwarf shrubs are Glubelaria cordifolia, Festuca sp. and Thymus serpyllum.

\subsection{Quantification of soil erosion}

Soil erosion rates were measured with two independent techniques. Sediment traps enabled the direct measurement of erosion rates during the growing season. Long-term erosion rates can be estimated by Cs-137 isotope analysis as indirect method. This method considers the redistribution of Cs-137 after its deposition in the year 1986 by the Chernobyl accident. The Cs-137 method delivers an integral value including winter and growing season processes.

\subsubsection{Sediment traps}

Sediment traps for erosion rate measurements were installed at each plot in July 2006 (Fig. 2) to measure erosion rates during the growing season. A geotextile which is fixed to the ground was used to detain the transported particles (Robichaud and Brown, 2002). The sediment trap was equipped with a v-shaped steel plane below the geotextile to collect and quantify the surface water flow (Fig. 2c). The quantification of the overland flow was done with a two-bowl tipping bucket (Fig. 2d). Each bowl had a capacity of 0.51 (EnvironmentalProducts, 2006).

Material that is transported into the geotextile was collected and weighted every second or third week during the growing season from April to November. In addition, at one plot of each land use type (hf3, pawo2, paw2), precipitation and soil moisture were measured continuously every 10 minutes. Precipitation was measured with tipping buckets (ECRN-50 rain gauge, DecagonDevices), soil mois- ture was measured with an EC-5 sensor (precision $\pm 2 \%$ ), (DecagonDevices). All data were logged by means of an Em50 Data Logger (DecagonDevices). It is likely that the used sediment traps tends to underestimate the surface water flow. The underestimation is due to small gaps between soil and geotextile at the upslope edge of the sediment trap inlet. Surface flow might therefore partially trickle away. However, we installed the sediment traps in July 2006 one year before the beginning of the experiments. This ensured the recovery of the soil edges and the surface cover and, therefore, mitigated the above mentioned error. The measurement period presented in this study of the sediment traps was from 2 April 2007 to 1 November 2007.

\subsubsection{Cesium-137}

As sediment traps provide information on total erosion for single growing seasons, long-term information of soil erosion of all plots was obtained from Cs- 137 measurements conducted in autumn 2007. Cs-137 measurements for the determination of soil erosion rates since the fallout of Cs137 (Chernobyl accident in April 1986) is a common in the low lands (e.g. Ritchie and McHenry, 1990; Walling and He, 1999), but has only been recently used in subalpine terrain (Konz et al., 2009). We used a NaI scintillation detector for Cs-137 measurement on our nine subalpine test plots. For the measurement procedure, the $\mathrm{NaI}$ scintillation detector was placed perpendicular to the ground at a height of $25 \mathrm{~cm}$ and measured for $1 \mathrm{~h}$. To estimate the erosion rate from Cs-137 measurement we require the depth distribution of the Cs-137 concentration within the soil. The depth distribution was measured for a soil core taken at the reference sites. The soil core was portioned into slices of $2.5 \mathrm{~cm}$ thickness and the Cs-137 activity was measured in the laboratory with a GeLi-detector. We found that the Cs-137 concentration decreases logarithmically with depth, whereby the concentration reduces by the half about every $5 \mathrm{~cm}$. The reference sites were chosen at places that are influenced neither by erosion nor deposition. Both reference sites are located at the valley bottom. Deposition of eroded soil on the reference sites can be excluded because of lateral moraines between the steep slopes and the reference sites. Soil erosion on both reference sites is unlikely due to a constant $100 \%$ vegetation cover since 1986. This can be confirmed from air photographs that were taken regularly since 1986. Additionally, the slope of both reference sites is $0 \%$. For further details please see Konz et al. (2009).

\subsection{Description of WEPP}

WEPP is a physically based simulation model (Flanagan and Nearing, 1995) that describes mechanisms controlling water induced erosion including anthropogenic impacts such as irrigation, grazing, cutting and ploughing. The hill slope version (v2008.907) of WEPP contains nine components: a 


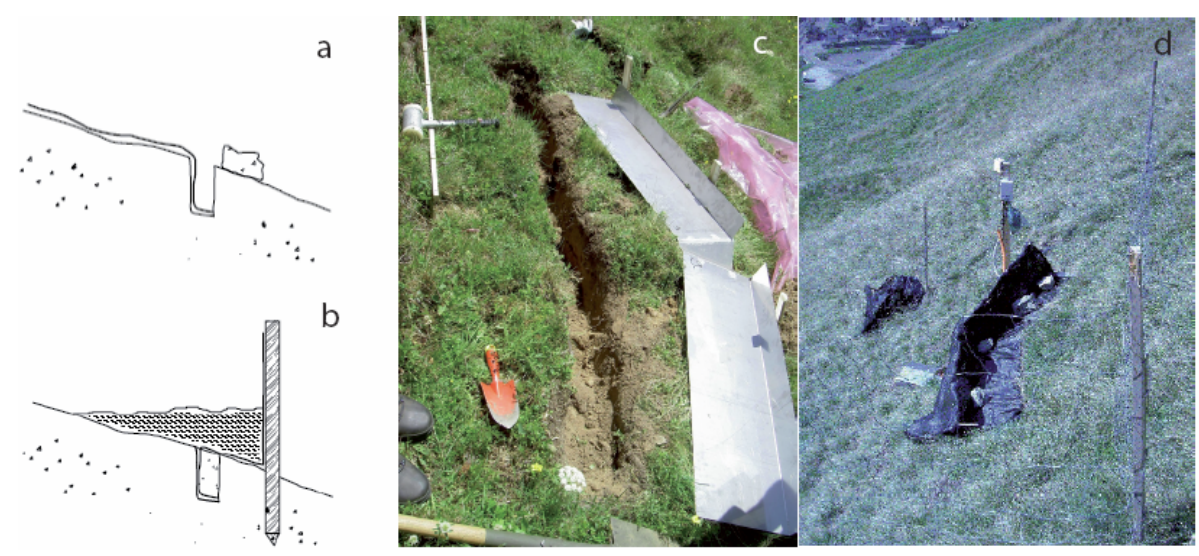

Fig. 2. (a)+(b) Sediment trap after Robichaud et al. (2002) and (c) extended version under construction in the Urseren Valley (2006) with a steel plate to concentrate the surface flow. The steel plate was finally attached to the upper boundary of the filled trench where the geotextile comes out of the trench. (d): completed sediment trap for erosion measurement at land use type hayfield (hf3).

Table 1a. Soil parameter for the three investigated hayfields (grain size analyses are given in $\%$ weight of fine-grained soil $<2000 \mu \mathrm{m}$ ). The maximum standard deviation due to the heterogeneity within single plots $(n=10)$ is $10 \%$ for grain size analyses, $9.5 \%$ for organic matter, $4.8 \%$ for $\mathrm{pH}$ value, $5 \%$ for fractional vegetation cover and $4.5 \%$ for slope steepness (for all three Tables $1 \mathrm{a}, \mathrm{b}$ and $\mathrm{c}$ ).

\begin{tabular}{lcccccc}
\hline & \multicolumn{2}{c}{ hf1 } & \multicolumn{2}{c}{ hf2 } & \multicolumn{2}{c}{ hf3 } \\
\hline depth $[\mathrm{m}]$ & $0-0.1$ & $0.1-0.5$ & $0-0.1$ & $0.1-0.5$ & $0-0.1$ & $0.1-0.5$ \\
sand $(63-2000 \mu \mathrm{m})[\%]$ & 31.9 & 33.1 & 23.8 & 22.1 & 37.2 & 34.1 \\
silt $(2-63 \mu \mathrm{m})[\%]$ & 42.3 & 39.8 & 45.5 & 43.9 & 41.4 & 33.6 \\
clay $(<2 \mu \mathrm{m})[\%]$ & 13.7 & 16.1 & 15.3 & 13.8 & 16 & 12.6 \\
organic matter [\%] & 12.9 & 6.7 & 12.2 & 6.1 & 12.8 & 6.4 \\
pH value & 5.0 & na & 4.4 & na & 4.5 & na \\
fractional veg. cover [\%] & \multicolumn{2}{c}{92} & \multicolumn{2}{c}{95} & \multicolumn{2}{c}{90} \\
slope [ ${ }^{\circ}$ ] & \multicolumn{2}{c}{39} & \multicolumn{3}{c}{36} & \multicolumn{3}{c}{39} \\
\hline
\end{tabular}

weather generator, snow accumulation and ablation, irrigation, surface and subsurface hydrology, plant growth, residue decomposition, soils and erosion. The determined vegetation as well as variable stocking rates and the cattle trails (variable configuration of slope intersections) can be transcribed by the model. Furthermore, the winter hydrology component is designed to simulate snow accumulation, snow density, snowmelt, and soil frost and thaw, all on an hourly basis (Savabi et al., 1995). The WEPP model is well tested in low land applications and is suitable to simulate dominate erosion processes of the low lands. Mountain specific processes, e.g. animal induced gravity forcing and snow mechanical processes cannot be handled by the WEPP model. Thus, a comparison of simulation results with measured erosion rates by Cs-137 can not be expected due to the missing processes. However, the simulations can be used to separate the bulk erosion rates into sheet erosion (splash and interrill erosion) and mountain specific processes.

\subsection{WEPP inputs}

Four modules of the WEPP model can be modified by the user (delivering input information for the nine components that are described above). These four modules are climate (rainfall amount, duration and intensity of rainfall, wind velocity and direction, temperature, solar radiation and dew point temperature), slope, soil (albedo, initial water saturation, interrill and rill erodibility, critical shear parameter, hydraulic conductivity, cation exchange capacity and organic matter (Table 1) and management. For the climate description, field-observed precipitation, daily temperature, solar radiation and wind (velocity and direction) were used. The data were taken from the meteorological station located at the valley bottom (1400 $\mathrm{m}$ a.s.1.), whereas the investigation areas are at the south-facing slope (at about $1650 \mathrm{~m}$ a.s.l). Hence, temperature at single south facing plots is slightly higher (up to $2{ }^{\circ} \mathrm{C}$, depending on the sky cover) than at the valley bottom due to the increased incoming short-wave radiation on the inclined surfaces. 
Table 1b. Soil parameter for the three investigated pastures without dwarf shrubs.

\begin{tabular}{lccccccc}
\hline & \multicolumn{2}{c}{ pawo1 } & \multicolumn{2}{c}{ pawo2 } & \multicolumn{2}{c}{ pawo3 } \\
depth $[\mathrm{m}]$ & $0-0.1$ & $0.1-0.5$ & $0-0.1$ & $0.1-0.5$ & $0-0.1$ & $0.1-0.5$ \\
\hline sand $(63-2000 \mu \mathrm{m})[\%]$ & 24.6 & 24.3 & 25.2 & 22.1 & 27.4 & 28.2 \\
silt $(2-63 \mu \mathrm{m})[\%]$ & 38.2 & 37.8 & 32.4 & 34.6 & 30.1 & 31.4 \\
clay $(<2 \mu \mathrm{m})[\%]$ & 12.1 & 14.6 & 11.3 & 11.8 & 10.9 & 11.2 \\
organic matter \% & 12.6 & 6.3 & 12.8 & 6.4 & 12.2 & 6.1 \\
pH value of soil & 7.1 & na & 7.3 & na & 4.6 & na \\
fractional veg. cover [\%] & \multicolumn{2}{c}{65} & \multicolumn{2}{c}{62} & & \multicolumn{2}{c}{37} \\
slope [ ${ }^{\circ}$ ] & \multicolumn{2}{c}{38} & \multicolumn{3}{c}{38} & & \\
\hline
\end{tabular}

Table 1c. Soil parameter for the three investigated pastures with dwarf shrubs (paw).

\begin{tabular}{|c|c|c|c|c|c|c|}
\hline \multirow[b]{2}{*}{ depth [m] } & \multicolumn{2}{|c|}{ paw1 } & \multicolumn{2}{|c|}{ paw2 } & \multicolumn{2}{|c|}{ paw3 } \\
\hline & $0-0.1$ & $0.1-0.5$ & $0-0.1$ & $0.1-0.5$ & $0-0.1$ & $0.1-0.5$ \\
\hline sand $(63-2000 \mu \mathrm{m})[\%]$ & 23.1 & 27.0 & 22.6 & 25.9 & 28.6 & 31.5 \\
\hline silt $(2-63 \mu \mathrm{m})[\%]$ & 52.3 & 49.8 & 55.7 & 47.9 & 49.3 & 52.2 \\
\hline clay $(<2 \mu \mathrm{m})[\%]$ & 8.7 & 8.5 & 9.5 & 7.6 & 11.2 & 10.1 \\
\hline organic matter [\%] & 11.9 & 6.1 & 11.9 & 6.0 & 12.2 & 6.1 \\
\hline $\mathrm{pH}$ value of soil & 4.3 & na & 4.4 & na & 4.5 & na \\
\hline fractional veg. cover [\%] & \multicolumn{2}{|c|}{77} & \multicolumn{2}{|c|}{73} & \multicolumn{2}{|c|}{79} \\
\hline slope $\left[{ }^{\circ}\right]$ & \multicolumn{2}{|c|}{38} & \multicolumn{2}{|c|}{38} & \multicolumn{2}{|c|}{35} \\
\hline
\end{tabular}

The soil properties soil texture, cation exchange capacity (CEC) and organic matter content were determined for the first $50 \mathrm{~cm}(0-10$ and $10-50$, Table 1$)$ by laboratory measurements. Critical shear stress $(\tau \mathrm{c})$, interrill erodibility (Ki), rill erodibility $(\mathrm{Kr})$ and hydraulic conductivity were calculated based on equations of the WEPP User Summary (Flanagan and Livingston, 1995) depending on grain size analyses that were measured with 10 replicates at each plot (Table 1). An initial water saturation degree was set for all plots at $25 \%$ in January 2007, based on soil moisture measurements. As there is no rotation of management type and plant composition in this investigation area, one management type was assigned for each land use type, as well as one composition of plants for the entire period. The surface of grassland does not have the typical rill and interrill pattern that leads to the defined rill and interrill erosion. This process has been realized by adjusting the random roughness (range management file) based on field measurements. Thus, WEPP simulations are concentrated on interrill erosion (sheet erosion). For the initialisation of the model's storages and bio-activity simulations an artificial warming up period was constructed using 20 times the data of the year 2007. The model output stabilized after around 5 to 6 years (Fig. 3). The slight fluctuations in erosion rates are due to non-annual biomass cycles simulated by the model.

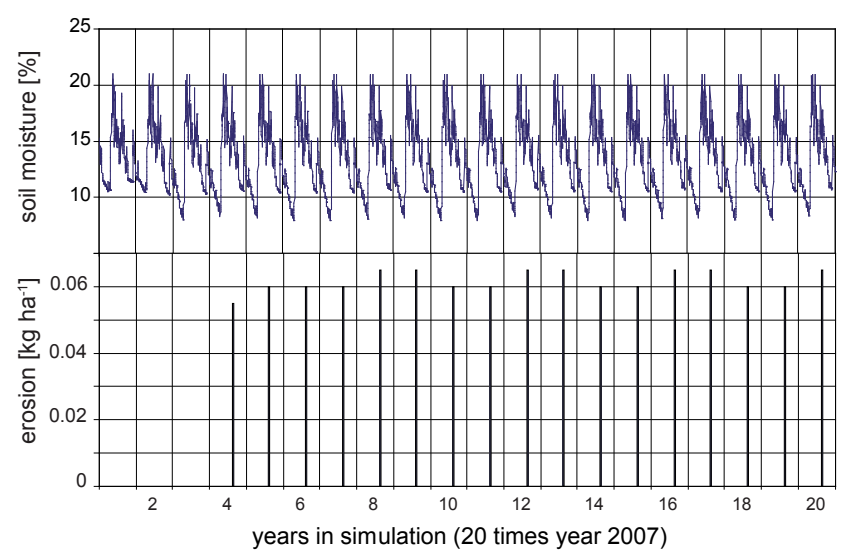

Fig. 3. Initialization of the WEPP model for the land use type hayfield for 20 times 2007. The same year was taken 20 times instead of a time series in order to identify the stabilization of the water amount and erosion processes independent of the variability of water amount from precipitation.

\subsection{Application of the WEPP model}

The calibration, we applied an experience based approach (Konz et al., 2007), takes our process knowledge gained from the measurement plots into account. Thus, an initial model parameter set was estimated according to measured system characteristics (e.g. soil texture, climate parameters, relief, fractional vegetation cover), available data from literature (e.g. rooting depth) and the parameter sets derived from 
Table 2. Monthly measured (meas.) and WEPP-simulated (simul.) erosion rates $\left(\mathrm{kg} \mathrm{ha}^{-1}\right)$ for the growing season April to November 2007 for the investigated three land use classes hayfield (hf), pasture without dwarf shrubs (pawo) and pasture with dwarf shrubs (paw). About $90 \%$ of all measured erosion rates is caused by gravity forcing. Erosion values that are due to sheet erosion (overland flow and splash erosion) are given in brackets behind the erosion values. For pawo it is even more than $95 \%$.

\begin{tabular}{lcccccc}
\hline & \multicolumn{2}{c}{ hf3 } & \multicolumn{2}{c}{ land use type } \\
& pawo2 & \multicolumn{2}{c}{ paw2 } \\
& meas. & simul. & meas. & simul. & meas. & simul. \\
\hline April & $0(0)$ & 0 & $39(<1.9)$ & 0 & $1(0.1)$ & 0 \\
May & $4.4(0.4)$ & 0.2 & $44(<2.2)$ & 0.3 & $8(0.8)$ & 0.2 \\
June & $1.3(0.1)$ & 0.1 & $22(<1.1)$ & 0.2 & $5(0.5)$ & 0.1 \\
July & $0.5(0.05)$ & 0 & $68(<3.4)$ & 0 & $11(1.1)$ & 0 \\
August & $1(0.1)$ & 0 & $62(<3.1)$ & 0.3 & $3(0.3)$ & 0 \\
September & $0(0)$ & 0 & $2(<0.1)$ & 0.1 & $3(0.3)$ & 0 \\
October & $0(0)$ & 0 & $1(<0.05)$ & 0 & $1(0.1)$ & 0 \\
\hline
\end{tabular}

earlier WEPP-applications in other basins (for the plant specific parameters). However, due to heterogeneity of soils and our inability to measure all model scale parameters (e.g. effective hydraulic conductivity that is derived from grain size analyses) the physically measured soil parameters usually cannot be taken one-by-one for the simulation. We therefore conducted a sensitivity analysis by varying one parameter and keeping the others fixed in order to identify the most sensitive parameters. The most sensitive parameters (precipitation amount and intensity, grain size, temperature, slope, canopy cover, random roughness, effective hydraulic conductivity) were considered in a Monte-Carlo analysis by allowing them to vary within reasonable ranges, which were defined by measurement uncertainty. 10000 runs were computed and the simulation results of overland flow and erosion were analyzed relative to the initial model parameter set. We found that the initial model parameter set, which is based on measurements and literature values, delivered reliable simulation results within the uncertainty ranges given by the Monte-Carlo simulations and we therefore used this parameter set for the simulation of the erosion rates. In fact, the model was most sensitive to changes in canopy cover and precipitation intensity allowing them to vary in a broader range. However, within the parameter range constrained by estimated measurement errors the sensitivity of the parameters significantly declined and with it the parameter uncertainty. This analysis was conducted to assess the predictive power of our initial model parameter set and it should be mentioned that it is not considered to be a thoroughly parameter uncertainty analysis. Please note, the model application is seen as a screening exercise to delineate sheet. WEPP does not simulate mountain specific processes. Therefore, we considered the experience based calibration, supported by Monte-Carlo analysis, as a suitable tool to differentiate between sheet erosion rates (simulated with WEPP) to total rates during growing season (sediment trap measurements) to total whole year erosion rates (Cs-137 measurements).

\section{Measurement results}

\subsection{Measured erosion rates during the growing season}

Erosion rates measured with sediment traps yielded in comparable results during 2006 and 2007. Two dominant erosion processes were identified during the growing season: (i) relocation of grains by sheet erosion processes and (ii) soil conglomerate movement triggered by animal trampling and followed by gravity forcing. Total monthly erosion rates ranged from 0 to $4.4 \mathrm{~kg} \mathrm{ha}^{-1}$ for hayfields (hf), from 1 to $68 \mathrm{~kg} \mathrm{ha}^{-1}$ for pasture without dwarf shrubs (pawo) and from 1 to $11 \mathrm{~kg} \mathrm{ha}^{-1}$ for pasture with dwarf shrubs (paw) (Table 2). Soil conglomerates were observed regularly in the sediment traps with diameters up to $30 \mathrm{~cm}$ (Fig. 4) during field observations in 2007 mostly on the land use type pasture without dwarf shrubs. These eroded soil pieces cannot be explained with the movement of soil particles through overland flow and splash erosion but rather by animal activity and the steepness of the slopes, where soil conglomerates are subject to gravity forcing. In order to separate between the two erosion processes we weighted the conglomerates and the fine soil material separately. This separation process resulted in a fraction of soil from sheet erosion of about 5-10\% (Table 2) compared to a much larger fraction of $90-95 \%$ due to gravity forcing process. The method tends to even overestimate sheet erosion rates because soil particles detach from the conglomerations while falling into the trap. The highest difference of total erosion rates can be observed at the land use site pasture without dwarf shrubs. Reasons for this could be the use of rangeland with higher trampling damage. Dwarf shrubs obviously reduce sediment transport. This can be explained with the hindering effect of dwarf shrubs on the transport of soil particles (Konz et al., 2009). Hayfields seem to be generally less susceptible to sheet erosion than pastures during the growing season. In general, erosion rates are very low, compared to observations in agricultural low lands. 


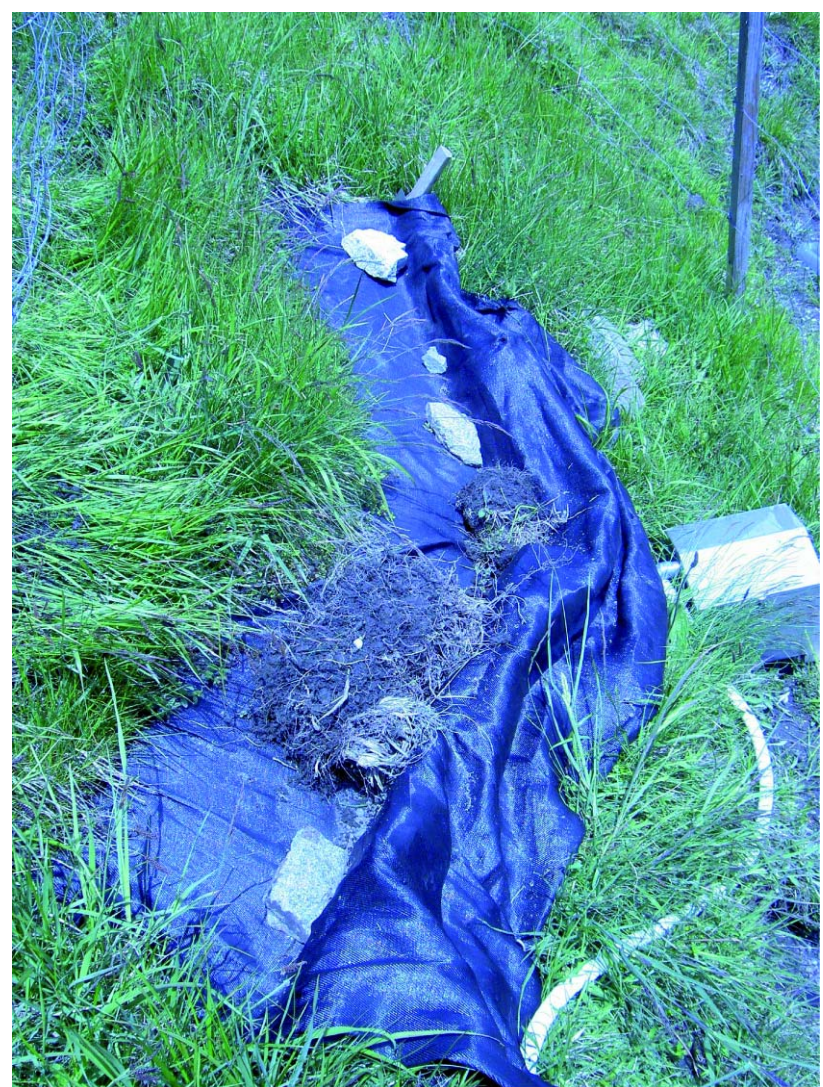

Fig. 4. Soil erosion during the growing season 2007. Large soil conglomerates were collected in the sediment traps ranging from 1 to $30 \mathrm{~cm}$.

\subsection{Long term erosion rates}

The long term Cs-137 erosion rates expressed as mean annual rates were about three magnitudes larger than the rates observed for the growing season at all nine plots (Fig. 5). It is very unlikely that inter annual variability and single high erosion years/events on specific plots are responsible for the observed discrepancy between the long term averaged high annual erosion rates and the measured low erosion rates during to growing seasons. Instead, it is very likely that winter processes such as freezing and thawing and snow cover dynamics trigger high erosion rates.

Contradictory to the seasonal erosion rates the highest annual rates $\left(\sim 35 \mathrm{tha}^{-1} \mathrm{a}^{-1}\right)$ could be found on hayfields. Mean annual erosion rates of pastures without dwarf shrubs are higher than erosion rates on pastures with dwarf shrubs (two to four times). This observation is congruent with the growing season measurements.

The variability of the long term mean annual erosion values on hayfields (hf1-hf3) is quite high ranging from $10 \mathrm{tha}^{-1} \mathrm{a}^{-1}$ up to $37 \mathrm{tha}^{-1} \mathrm{a}^{-1}$. In contrast, the variability between the three replicates of pasture with dwarf shrubs (paw1-paw3) and pasture without dwarf shrubs

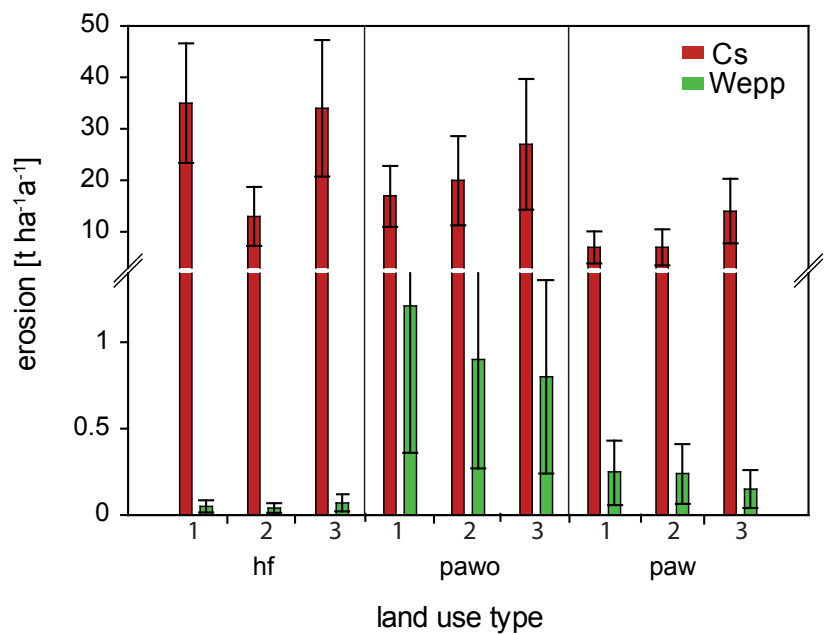

Fig. 5. Mean annual erosion rates of WEPP simulation compared to Cs-137-based erosion rates of all investigation plots for the period 1986-2007. Cs-137 error bars are due to manual analysis of gamma spectra $(17 \%)$, the heterogeneity of each single plot $(n=3$; mean standard deviation $10.1 \%$ ) and uncertainty of soil porosity. WEPP errors result from sensitivity analysis.

(pawo1-pawo3) is lower (ranging from $7 \mathrm{tha}^{-1} \mathrm{a}^{-1}$ up to $13 \mathrm{tha}^{-1} \mathrm{a}^{-1}$ for paw and from $20 \mathrm{tha}^{-1} \mathrm{a}^{-1}$ up to $29 \mathrm{tha}^{-1} \mathrm{a}^{-1}$ for pawo).

The reason for the high spatial and temporal variability of the hayfields' erosion could be the high avalanche activity on the hayfield sites (Ambuehl, 1961). Furthermore, we observed a high influence of snow gliding processes (see Fig. 6). Ambuehl (1961) determined the avalanche activities on the slopes of the Urseren Valley and developed an avalanche map that was compared with our study sites. Additional regular field visits and qualitative avalanche monitoring (simple counting of avalanches on the specific sites) during winter 2007/2008 confirmed Ambuehl's results. The site hf 3 experiences regularly a high avalanche activity. Neither avalanches nor snow gliding processes were observed on hf2 by Ambuehl (1961) and during our investigation period.

\section{Simulation results of the WEPP model}

As discussed in Sect. 2.4 the WEPP model simulates the sheet erosion, namely splash erosion and interrill erosion (rill erosion was not modeled because of the failing rill-interrill shape). In order to assess the model performance and the reliability of the simulated erosion amounts we can compare results of the hydrology modules (overland flow and soil moisture) to plots measurements (hf3, pawo2, paw2). 


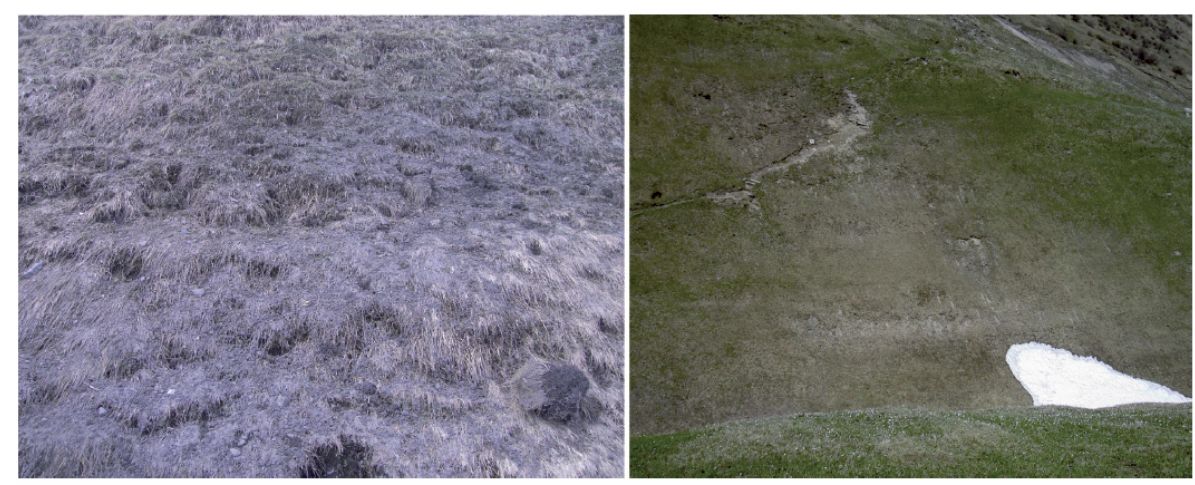

Fig. 6. Investigation site pawo 2 (left hand side) and hf1 (right hand side) shortly after snow melt. This picture gives an impression of the possible influence of snow and "snow gliding" on erosion processes.

\subsection{Hydrology}

The hydrology (overland flow and soil moisture content) was simulated well during the growing season from April to October 2007 (Fig. 7). Simulated overland flow compares well with the measurements for all land use types (for example see simulation results and measurements of the land use type hayfield, Fig. 7). Overestimations of overland flow occurred in May, June and August (42\%, 33\% and 53\%, respectively). The sediment traps with equipment for overland flow measurement tend to underestimate the surface flow (see Sect. 2.3.1). Thus, the simulation bias falls within the expected error of the observed flow rates. Interestingly, in July, September and October surface flow is observed but not simulated.

The dynamic of the observed soil moisture is reproduced well for all land use types (Fig. 7) from the end of April onwards and even very specific patterns of the soil moisture dynamics are simulated well for the land use type pasture without dwarf shrubs (pawo). A general underestimation of about 5\% during summer time can be observed for the land use types pasture with dwarf shrubs (paw) and hayfields (hf), but dynamics are reproduced satisfactory throughout the entire growing season. A possible reason could be an overestimation of evapotranspiration with values of about $2.4 \mathrm{~mm} \mathrm{day}^{-1}$ (mean values during growing season) for hayfields and $3.2 \mathrm{~mm} \mathrm{day}^{-1}$ for dwarf shrubs (mean values during growing season). Fecht et al. (2005) provides values of about $1.7 \mathrm{~mm} \mathrm{day}^{-1}$ (mean values during growing season) for hayfields and $2.8 \mathrm{~mm} \mathrm{day}^{-1}$ (mean values during growing season) for dwarf shrubs in mountainous environments.

Significant discrepancies between measurements and observations of soil moisture both in terms of dynamics and absolute values can be observed in the end of March and beginning of April (Fig. 7c-e). Measurements and simulations show contradictory patterns with increasing simulated soil moisture and decreasing measured soil moisture. Reasons for that could be wrong assumption of snow accumulation and ablation calculations in WEPP (Figure not shown). However, the model performance was satisfying during the major part of the growing season when snow accumulation and ablation processes did not have any influence (Fig. 7c-e).

Since the hydrology dominates the erosion processes a reliable simulation of overland flow is a prerequisite for erosion predictions. The WEPP model reproduces the overland flow rates with acceptable accuracy and therefore provides reliable inputs for the erosion module. Although the model overestimates the observed runoff rates it should be considered that the measurement of overland flow is subject to measurement errors (underestimation, see Sect. 2.3.1). Thus, the simulation results are considered to be within a range that is satisfying and can be considered as appropriate for erosion simulations. Since the erosion processes are simulated with equations which only use surface water level as transient variable the hydrological input is the most important input that can be related to internal model performance assessments. The additional information required for erosion simulations, e.g. land use and soil parameters, are externally derived parameters and the errors caused by those values cannot be considered as internal model uncertainties. We therefore consider the WEPP model simulations as reliable and suitable to reproduce the erosion rates caused by the sheet erosion processes during the growing season.

\subsection{Simulated soil erosion rates during the growing season}

Table 2 compares the simulated and the measured sheet soil erosion rates during the growing season 2007. The measured values of sheet erosion rates (without conglomerates due to gravity forcing) were generally very low (Table 2). The model simulates erosion rates in the same order of magnitude for all three investigated land use types. As given in Table 3 only the growing season of paw 2 shows significant differences compared to our observation year 2007. The 2007 simulation delivers a sheet erosion rate of $0.3 \mathrm{~kg} \mathrm{ha}^{-1} \mathrm{a}^{-1}$ for 
Table 3. Comparison of simulated erosion rates 1986-2007 during the growing season (April-October) and simulated erosion rates including the whole year (January-December) from 1986-2007. Cumulative erosion rates are given in $\mathrm{kg} \mathrm{ha}^{-1} \mathrm{a}^{-1}$.

\begin{tabular}{|c|c|c|c|c|c|c|}
\hline \multirow[b]{2}{*}{ season } & & & $\begin{array}{r}\text { land } \\
\mathrm{p}\end{array}$ & $\begin{array}{l}\text { e type } \\
\text { o2 }\end{array}$ & & \\
\hline & $\begin{array}{l}\text { growing } \\
\text { period }\end{array}$ & $\begin{array}{c}\text { complete } \\
\text { season }\end{array}$ & $\begin{array}{l}\text { growing } \\
\text { period }\end{array}$ & $\begin{array}{l}\text { complete } \\
\text { season }\end{array}$ & $\begin{array}{l}\text { growing } \\
\text { period }\end{array}$ & complete \\
\hline$\Sigma 1986-2007$ & 5 & 154 & 40 & 20900 & 140 & 4400 \\
\hline
\end{tabular}

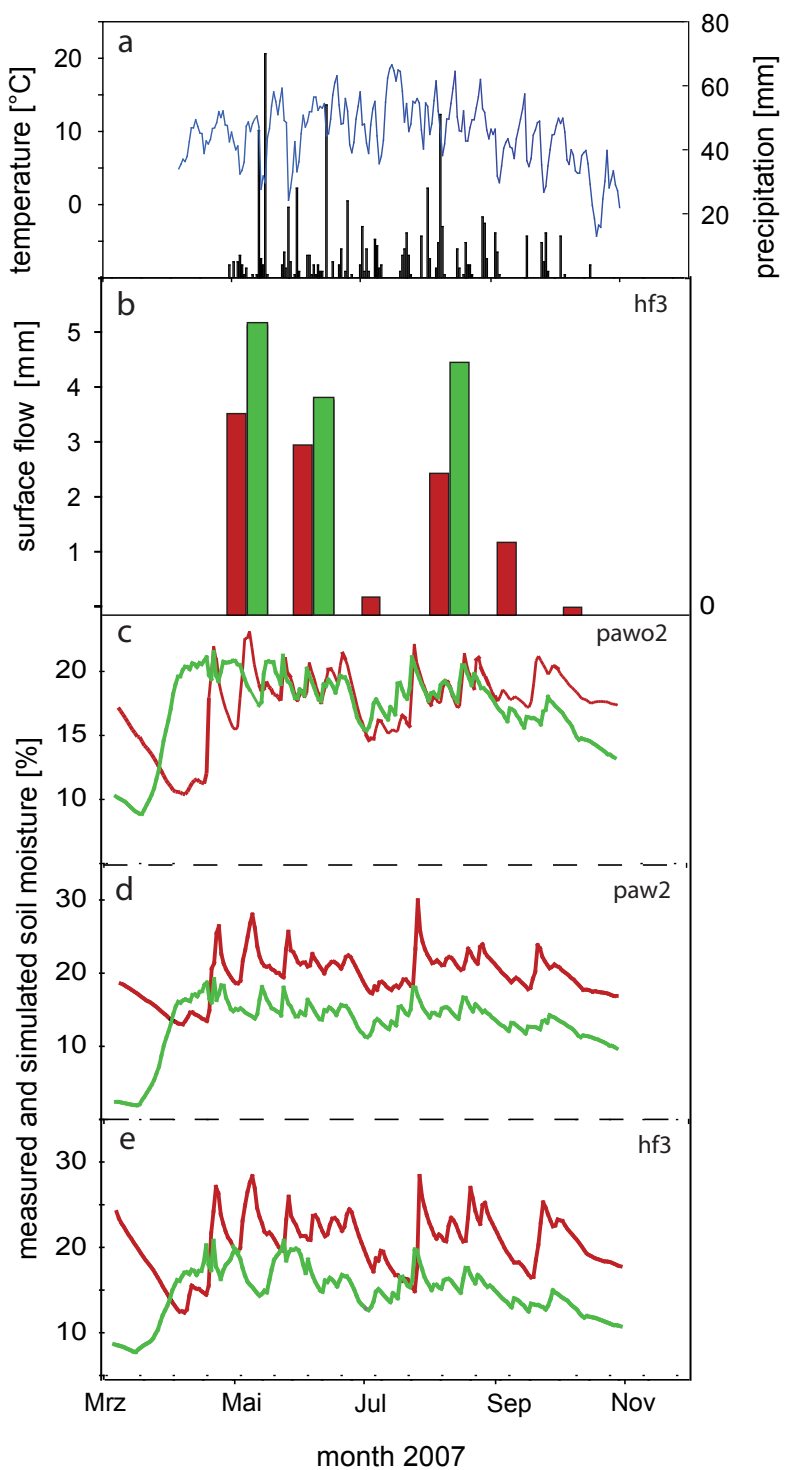

Fig. 7. (a) measured daily precipitation (black) and mean air temperature (blue), (b) measured (red) and simulated (green) surface flow for hf3. (c)-(e) measured (red) and WEPP simulated (green) soil water content for April to November 2007 for one of all three land use types pasture without dwarf shrubs (pawo2), pasture with dwarf shrubs (paw2) and hayfield (hf3) for the upper $35 \mathrm{~cm}$. the growing season compared to the simulated mean long term value of sheet erosion of $6.4 \mathrm{~kg} \mathrm{ha}^{-1} \mathrm{a}^{-1}$ (value of Table $3,140 \mathrm{~kg} \mathrm{ha}^{-1}$ divided by 22 years). This deviation is most likely due to extreme precipitation events that have a higher influence on erosion processes on pastures due to less vegetation cover. No extreme rainfall events occur during our measurement period (Fig. 8). However, even if we consider the simulated mean long-term erosion value for paw2 it is significantly lower than the measured total erosion rate during growing season in $2007\left(32 \mathrm{~kg} \mathrm{ha}^{-1}\right.$, sum of paw2 in Table 2). Therefore, the model proves the right magnitude of the measured sheet erosion rates for all land use types. The simulated mean annual rates are significantly higher than the corresponding rates of the growing season.

Generally, our measured soil erosion rates during the growing season are low but comparable to the measured erosion rates of Felix and Johannes (e.g. Felix and Johannes, 1995) (0.1 to $\left.200 \mathrm{~kg} \mathrm{ha}^{-1}\right)$ in the Berchtesgaden region (South Germany, Bavarian Alps). They conclude that their low erosion rates are based on low effective precipitation that is between 1 and $2 \%$. The effective precipitation on our investigation plots is comparable and ranges between $0.6 \%$ and $2 \%$ during the growing season. Frankenberger (1995) measured much higher erosion rates during the growing season up to $20000 \mathrm{~kg} \mathrm{ha}^{-1}$. However, he reported that the effective precipitation during the investigation period was up to $60 \%$.

Extreme erosion rates (low as well as high rates) are generally challenging for soil erosion modeling (Nearing, 1998). Thus, the inaccuracy of simulated erosion values is a general problem of models and not a specific problem of the WEPP model. This is shown in the study of Simonato et al. (2002). They did erosion simulations based on the WEPP model and the RUSLE that were compared to plot measurements in the Italian Alps. The study was done during the growing season 1998 and 1999. The lowest measured values were $0 \mathrm{~kg} \mathrm{ha}^{-1}$, highest values $3000 \mathrm{~kg} \mathrm{ha}^{-1}$. For those plots WEPP simulations resulted in erosion rates of $210 \mathrm{~kg} \mathrm{ha}^{-1}$ and $4720 \mathrm{~kg} \mathrm{ha}^{-1}$, respectively. Results of the RUSLE are $39000 \mathrm{~kg} \mathrm{ha}^{-1}$ and $41000 \mathrm{~kg} \mathrm{ha}^{-1}$, respectively. Based on this study the WEPP model seems to be more useful for the prediction of low mountainous erosion rates during the growing season. Moreover, it could be shown that some further 
Table 4. Relative contributions of the three process classes identified for the Urseren Valley.

\begin{tabular}{|c|c|c|c|}
\hline & $\begin{array}{l}\text { hf3 } \\
(\%)\end{array}$ & $\begin{array}{c}\text { pawo2 } \\
(\%)\end{array}$ & $\begin{array}{c}\text { paw2 } \\
(\%)\end{array}$ \\
\hline Gravity forcing & 0.019 & 1.13 & 0.36 \\
\hline Sheet erosion & 0.0019 & 0.06 & 0.04 \\
\hline Winter erosion & 99.98 & 98.81 & 99.60 \\
\hline
\end{tabular}

studies confirm low erosion rates during the growing season in mountainous regions (Felix and Johannes, 1995; Simonato et al., 2002).

\section{Relative contribution of soil erosion processes}

Although a direct comparison of measured long term and seasonal data is difficult due to the different time windows of observation (the long term annual value is the average erosion rate of 22 years compared to the seasonal data of seven months), this comparison gives a good indication of the dominant erosion processes at our subalpine sites. From the longterm measurements, the sediment trap measurements, and the modeling exercises, we can distinguish between three major process classes: (i) the direct measurements of gravity forcing processes and sheet erosion processes during growing season, (ii) the modeling of sheet erosion and (iii) the indirectly inferred contribution of winter processes delineated from the difference between Cs-137 derived erosion rates and modeled erosion rates (Fig. 9). Based on our combined measurement and simulation analyses we can provide first quantitative measures of the relative contributions of each subprocess (Table 4). Erosion processes during the growing season are negligible small compared to the winter processes. Gravity forcing and development of soil conglomerates due to animal activity dominate the growing season. Since the highest erosion rates were measured on slopes that are reported to have a high avalanche risk or are prone to snow gliding during winter time (hf1, pawo3 and hf3) it is very likely that those processes are responsible for the high erosion rates. Furthermore, the discrepancy between the high Cs-137 based erosion rates and the measured or simulated rates are most likely attributed to winter processes because (i) we measured summer processes and (ii) these winter processes are not implemented in WEPP, thus explaining the failure of the model. However, the influence of snow mechanical processes is so far poorly understood and has to be investigated in more detail in the future.

\section{Conclusions}

We distinguished between the dominant erosion processes in mountainous environments. The low measured erosion rates were confirmed by simulations with the physically based

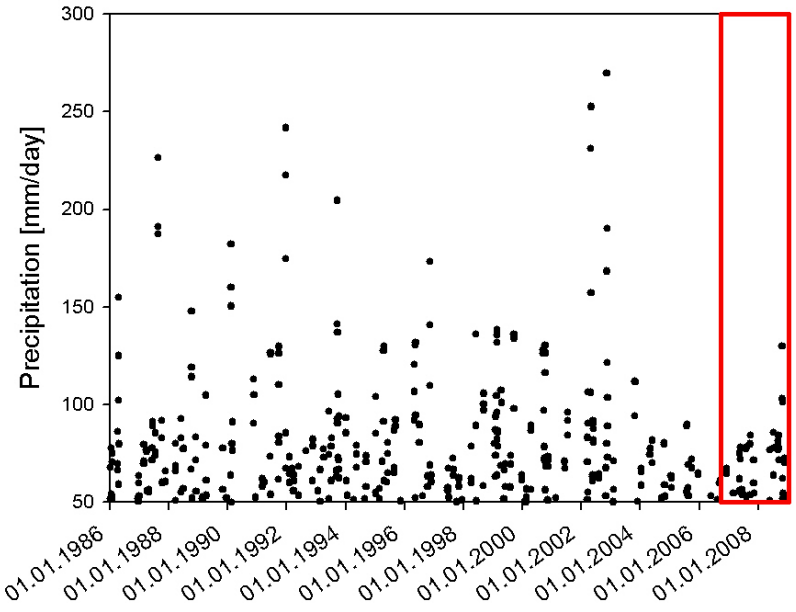

Fig. 8. Daily sums of precipitation ( $>50 \mathrm{~mm}$ ) from 1986 to 2008 . Red box marks the time period were erosion rates were measured with sediment traps.

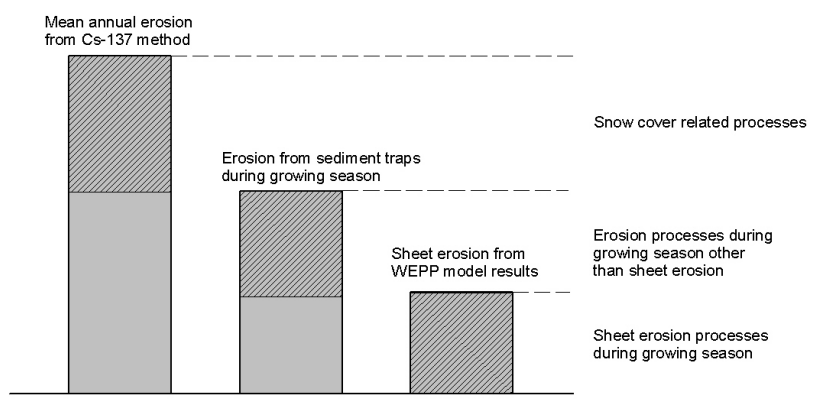

Fig. 9. Conceptual results of process identification approach; marked parts of the bars indicate the respective processes, whereas the entire bar shows the total measured value. The process separation was done by calculating the relative differences between the annual rate, the growing season measurements and the model simulations during the growing season.

model WEPP. We consider the WEPP simulations to be reliable because the driving transient hydrological variables are reproduced with acceptable accuracy. WEPP failed to capture the high mean annual (1986-2007) erosion rates as indicated by Cs- 137 measurements. We interpreted the latter differences to be due to winter processes which are not included in the WEPP simulation. Besides sheet erosion processes, random gravity driven movements of conglomerates following animal trampling could be distinguished. While gravity driven soil erosion rates were already 20 times higher than sheet erosion rates, but the by far highest fraction $(\sim 99 \%)$ of erosion is caused by winter processes as identified by Cs- 137 measurements. The winter processes were dominant for all our nine investigation plots. Therefore it is unlikely that single high erosion events are responsible for the high values. 
Regarding model performance we conclude that the model reproduces sheet erosion processes and can therefore be used to differentiate between confounding factors of erosion in mountain systems but cannot be used to simulated whole year erosion rates in systems where winter processes dominate erosion rates. This WEPP application was the first comparison between high temporal resolute field installations (erosion, soil moisture, and surface flow measurements) and WEPP simulations in mountainous areas.

The analysis of measurements and simulations indicated that winter processes have to be investigated further; most likely avalanche activity and snow gliding processes are mainly relevant for sediment detachment and transport. Future research should concentrate on interface processes between soil and snow cover, e.g. friction and abrasion. As stated the numbers presented here are first estimates and need further measurements to prove the generality of our results.

Acknowledgements. This work was financially supported by the State Secretariat for Education and Research (SER), in the framework of the European COST action 634: "On- and Off-site Environmental Impacts of Runoff and Erosion".

Edited by: J. Freer

\section{References}

Alewell, C., Meusburger, K., Brodbeck, M., and Banninger, D.: Methods to describe and predict soil erosion in mountain regions, Landscape Urban Plan., 88, 46-53, 2008.

Ambuehl, E.: 100 Jahre Einschneien und ausapern in Andermatt, Sonderausdruck aus dem Quartalsheft 4, Die Alpen, 1961.

Appenzeller, C., Beyert, M., Zenklusen, E., and Scherrer, S. C.: Monitoring climate at Jungfraujoch in the high Swiss Alpine region, Sci. Total Environ., 391, 262-268, doi:10.1016/j.scitotenv.2007.10.005|ISSN0048-9697, 2008.

Brazier, R. E., Beven, K. J., Freer, J., and Rowan, J. S.: Equifinality and uncertainty in physically based soil erosion models: Application of the glue methodology to WEPP-the water erosion prediction project-for sites in the UK and USA, Earth. Surf. Proc. Land., 25, 825-845, 2000.

Descroix, L. and Mathys, N.: Processes, spatio-temporal factors and measurements of current erosion in the French Southern Alps: A review, Earth. Surf. Proc. Land., 28, 993-1011, doi:10.1002/esp.514, 2003.

EnvironmentalProducts: Analytic of environmental Products, Cottbus, http://www.upgmbh.com/, 2006.

Fecht, M., Höfle, B., Starnberger, R., and Kaser, G.: Eine Karte der aktuellen Verdunstung für das Tirol Atlas Gebiet anhand von Landnutzungs- und Vegetationsdaten, Eine Karte der aktuellen Verdunstung für das Tirol Atlas Gebiet anhand von Landnutzungs- und Vegetationsdaten, 2005.

Felix, R. and Johannes, B.: Bodenerosionsuntersuchungen auf Testparzellen im Kalkhochgebirge, Mitteilungen der Oesterreichischen Geographischen Gesellschaft, 137, 76-92, 1995.
Flanagan, D. C. and Livingston, S. J.: Water Erosion Prediction Project (WEPP) Version 95.7 User Summary, Agricultural Research Service, NSERL Report No. 11, 1-141, 1995.

Flanagan, D. C. and Nearing, M. A.: USDA-Water Erosion Prediction Project: Hillslope Profile and Watershed Model Documentation, National Soil Erosion Research Laboratory, West Lafayette, 10, 298 pp., 1995.

Frankenberg, P., Geier, B., Prostwitz, E., Schütz, J., and Seeling, S.: Investigation on soil erosion and solid matter transport in the Gunzrieder valley/Oberallgäu, Investigation on soil erosion and solid matter transport in the Gunzrieder valley/Oberallgäu, 114, 213-231, 1995.

Fuhrer, J., Beniston, M., Fischlin, A., Frei, C., Goyette, S., Jasper, K., and Pfister, C.: Climate risks and their impact on agriculture and forests in Switzerland, Climatic Change, 79, 79-102, doi:10.1007/s10584-006-9106-6|ISSN 0165-0009, 2006.

Govers, G., Lobb, D. A., and Quine, T. A.: Preface - Tillage erosion and translocation: emergence of a new paradigm in soil erosion research, Soil Till. Res., 51, 167-174, 1999.

Gronsten, H. A. and Lundekvam, H.: Prediction of surface runoff and soil loss in southeastern Norway using the WEPP Hillslope model, Soil Till. Res., 85, 186-199, doi:10.1016/j.still.2005.01.008|ISSN 0167-1987, 2006.

Hessel, R., Jetten, V., and Zhang, G. H.: Estimating Manning's n for steep slopes, Catena, 54, 77-91, 2003.

Huang, C. H., Bradford, J. M., and Laflen, J. M.: Evaluation of the detachment-transport coupling concept in the WEEP rill erosion equation, Soil Sci. Soc. Am. J., 60, 734-739, 1996.

Isselin-Nondedeu, F. and Bedecarrats, A.: Influence of alpine plants growing on steep slopes on sediment trapping and transport by runoff, Catena, 71, 330-339, doi:10.1016/j.catena.2007.02.001|ISSN 0341-8162, 2007.

IUSS Working Group WRB: World Reference Base for Soil Resources Reports No. 103, FAO, Rome, Italy, 2006.

Kaegi, H. U.: Die traditionelle Kulturlandschaft im Urserental, Beitrag zur alpinen Kulturgeographie, 212 pp., 1973.

Konz, M., Uhlenbrook, S., Braun, L., Shrestha, A., and Demuth, S.: Implementation of a process-based catchment model in a poorly gauged, highly glacierized Himalayan headwater, Hydrol. Earth Syst. Sci., 11, 1323-1339, 2007, http://www.hydrol-earth-syst-sci.net/11/1323/2007/.

Konz, N., Schaub, M., Prasuhn, V., and Alewell, C.: Cs-137 based erosion rate determination of a steep mountainous region, J. Plant Nutr. Soil Sc., 172, 615-622, 2009.

Laflen, J. M., Flanagan, D. C., and Engel, B. A.: Soil erosion and sediment yield prediction accuracy using WEPP, J. Am. Water Resour. As., 40, 289-297, 2004.

Laternser, M. and Schneebeli, M.: Long-term snow climate trends of the Swiss Alps (1931-99), Int. J. Climatol., 23, 733-750, 2003.

Nearing, M. A.: Why soil erosion models over-predict small soil losses and under-predict large soil losses, Catena, 32, 15-22, 1998.

Nearing, M. A., Pruski, F. F., and O’Neal, M. R.: Expected climate change impacts on soil erosion rates: A review, Expected climate change impacts on soil erosion rates: A review, J. Soil Water Conserv., 59, 43-50, 2004.

Pieri, L., Bittelli, M., Wu, J. Q., Dun, S., Flanagan, D. C., Pisa, P. R., Ventura, F., and Salvatorelli, F.: Using the Water Erosion Pre- 
diction Project (WEPP) model to simulate field-observed runoff and erosion in the Apennines mountain range, Italy, J. Hydrol., 336, 84-97, 2007.

Raclot, D. and Albergel, J.: Runoff and water erosion modelling using WEPP on a Mediterranean cultivated catchment, Phys. Chem. Earth, 31, 1038-1047, doi:10.1016/j.pce.2006.07.002|ISSN 1474-7065, 2006.

Ritchie, J. C. and McHenry, J. R.: Application of radioactive fallout cesium-137 for measuring soil-erosion and sediment accumulation rates and patterns - A review, J. Environ. Qual., 19, 215233, 1990.

Robichaud, P. R. and Brown, R. E.: Silt Fences: An Economical Technique for Measuring Hillslope Soil Erosion, Dept. Agriculture, General Technical Report RMRS-GTR-94, 1-24, 2002.

Savabi, M. R., Young, R. A., Benoit, G. R., Witte, J. M., and Flanagan, D. C.: Winter hydrology. Chapter 3 in: USDA-Water Erosion Prediction Project (WEPP) Hillslope Profile and Watershed Model Documentation, edited by: Flanagan, D. C. and Nearing, M. A., J. Irrig. Drain. E.-Asce, 18, 1993.
Savabi, M. R., Rawls, W. J., and Knight, R. W.: Water Erosion Prediction Project (WEPP) Rangeland Hydrology Component Evaluation on a Texas Range Site, J. Range Manage., 48, 535-541, 1995.

Simonato, T., Bischetti, G. B., and Crosta, G. B.: Evaluating soil erosion with RUSLE and WEPP in an alpine environment (Dorena Valley - Central Alps, Italy), Sustain. Land Manage. Environ. Prot., 35, 481-494, 2002.

Walling, D. E. and He, Q.: Improved models for estimating soil erosion rates from cesium-137 measurements, J. Environ. Qual., 28, 611-622, 1999.

Yu, B. and Rosewell, C. J.: Evaluation of WEPP for runoff and soil loss prediction at Gunnedah, NSW, Australia, Austr. J. Soil Res., 39, 1131-1145, 2001. 